University of Nebraska - Lincoln

DigitalCommons@University of Nebraska - Lincoln

Faculty Papers and Publications in Animal

Science

Animal Science Department

7-11-2006

\title{
Bovine respiratory disease in feedlot cattle: Environmental, genetic, and economic factors
}

G. D. Snowder

USDA, ARS, US Meat Animal Research Center, Clay Center, NE

L. Dale Van Vleck

University of Nebraska-Lincoln, dvan-vleck1@unl.edu

L. V. Cundiff

USDA, ARS, US Meat Animal Research Center, Clay Center, NE

G. L. Bennett

USDA, ARS, US Meat Animal Research Center, gary.bennett@ars.usda.gov

Follow this and additional works at: https://digitalcommons.unl.edu/animalscifacpub

Part of the Animal Sciences Commons

Snowder, G. D.; Van Vleck, L. Dale; Cundiff, L. V.; and Bennett, G. L., "Bovine respiratory disease in feedlot cattle: Environmental, genetic, and economic factors" (2006). Faculty Papers and Publications in Animal Science. 118.

https://digitalcommons.unl.edu/animalscifacpub/118

This Article is brought to you for free and open access by the Animal Science Department at DigitalCommons@University of Nebraska - Lincoln. It has been accepted for inclusion in Faculty Papers and Publications in Animal Science by an authorized administrator of DigitalCommons@University of Nebraska - Lincoln. 


\title{
Bovine respiratory disease in feedlot cattle: Environmental, genetic, and economic factors
}

\author{
G. D. Snowder, ${ }^{11}$ L. D. Van Vleck, $\dagger$ L. V. Cundiff,* and G. L. Bennett* \\ *USDA, ARS, US Meat Animal Research Center, Clay Center, NE; \\ $\dagger$ USDA, ARS, US Meat Animal Research Center, Lincoln, NE
}

\begin{abstract}
The objective of this study was to characterize genetic, environmental, and economic factors related to the incidence of bovine respiratory disease (BRD) in feedlot calves. Records from 18,112 calves representing 9 breeds (Angus, Braunvieh, Charolais, Gelbvieh, Hereford, Limousin, Pinzgauer, Red Poll, and Simmental) and 3 composite types (MARC I, MARC II, and MARC III) over a 15-yr period (1987 to 2001) were evaluated. Disease incidence was observed and recorded by station veterinary and technical staff. The incidence of BRD varied across years, with the annual observed incidence ranging from 5 to $44 \%$. From 1987 to 1992 , the annual average incidence generally exceeded $20 \%$. However, in later years the annual incidence did not exceed $14 \%$. The epidemiological pattern indicated that BRD infection increased dramatically after $5 \mathrm{~d}$ on feed and remained high until approximately $80 \mathrm{~d}$ on feed. Previous BRD infection during the preweaning period did not influence subsequent BRD infection in the feedlot. Steers were more likely to become sick with BRD than heifers; castration before entry in the feedlot may be a predisposing cause. Few significant differences among breeds were detected for BRD incidence.
\end{abstract}

Adjusted solutions from mixed model analyses indicated that Herefords were generally more susceptible to BRD infection $(P<0.05)$ than MARC I and III composite types. Composite breed types had similar susceptibility compared with other purebred breeds. Mortality associated with BRD was greatest in Red Poll calves (9\%) compared with the average over all breeds (4\%). Estimates of heritability for resistance to BRD ranged from 0.04 to $0.08 \pm 0.01$. When the observed heritability was transformed to an underlying continuous scale, the estimate increased to 0.18. Selection for resistance to BRD could be effective if phenotypes for BRD resistance were known. Thus, development of an inexpensive and humane method of challenging animals with BRD to determine resistance would be an important step in reducing the incidence of BRD. This study also demonstrated that producer-collected field data could be used for selection against this disease. The economic loss associated with lower gains and treatment costs for BRD infection in a 1,000-cattle feedlot was estimated as $\$ 13.90$ per animal, not including labor and associated handling costs.

Key words: beef cattle, breed, disease resistance, growth, heritability, shipping fever

(c)2006 American Society of Animal Science. All rights reserved.

J. Anim. Sci. 2006. 84:1999-2008 doi:10.2527/jas.2006-046

\section{INTRODUCTION}

Bovine respiratory disease (BRD) is the most common and costly disease of feedlot cattle in the United States (Smith, 1998; NAHMS, 2000a). In 1999, most feedlots (97.4\%) within 12 states reported an overall BRD incidence of $14.4 \%$ (NAHMS, 2000a). Treatment costs for BRD averaged $\$ 15.57$ per sick animal. Costs are significantly greater when labor, isolation, increased time on feed, mortality, prophylaxis, and metaphylaxis treatments are considered (NAHMS, 2000a).

${ }^{1}$ Corresponding author: snowder@email.marc.usda.gov

Received January 25, 2006.

Accepted February 27, 2006.
Bovine respiratory disease is a complex of diseases characterized by many types of infection, each having its own causes, clinical signs, and economic implications. Prevalent microbial causes for BRD include viral (infectious bovine rhinotracheitis, bovine viral diarrhea, bovine respiratory syncytial, and parainfluenza type 3), bacterial (Mannheimia haemolytica, Pasteurella multocida, Haemophilus somnus), and mycoplasmal (Ellis, 2001).

Shipping and processing feedlot calves enhances predisposing causes and increases environmental risk factors. Predisposing causes (Callan and Garry, 2002) are generally synergistic and include age, stress (comingling, weather, nutritional changes, etc.), and immunological background. Environmental risk factors include climate, ambient temperature, dust particles, stocking 
Table 1. Number of sires, dams, and calves, years recorded, and data subsets analyzed by breed type and overall

\begin{tabular}{lrrrrl}
\hline \hline Breed & Sire & Dam & Calf & \multicolumn{1}{c}{ Year } & Subset $^{1}$ \\
\hline Angus & 124 & 866 & 2,127 & $1987-2001$ & EARLY, LATE, SELECT \\
Hereford & 102 & 677 & 1,649 & $1987-1999$ & EARLY, LATE, SELECT \\
Charolais & 104 & 615 & 1,883 & $1987-2001$ & EARLY, LATE, SELECT \\
Gelbvieh & 88 & 554 & 1,649 & $1987-2001$ & EARLY, LATE, SELECT \\
Red Poll & 26 & 191 & 387 & $1987-1991$ & EARLY \\
Simmental & 24 & 161 & 355 & $1987-1991$ & EARLY \\
Pinzgauer & 35 & 152 & 346 & $1987-1991$ & EARLY \\
Braunvieh & 30 & 176 & 380 & $1987-1991$ & EARLY \\
Limousin & 27 & 194 & 436 & $1987-1991$ & EARLY \\
MARC I & 155 & 1,091 & 2,974 & $1987-2001$ & EARLY, LATE, SELECT \\
MARC II & 139 & 1,011 & 2,962 & $1987-2001$ & EARLY, LATE, SELECT \\
MARC III & 118 & 1,065 & 2,964 & $1987-2001$ & EARLY, LATE, SELECT \\
\hline Overall & 972 & 6,213 & 18,112 & & \\
\hline
\end{tabular}

${ }^{1}$ Data subsets included breeds present within similar years: EARLY = 1987 through 1991; LATE = 1992 through 2001; SELECT = 1987 through 2001 .

density, humidity, ventilation, and shipping distance. Epidemiological factors include microbial agent(s), mode of transmission, parasite density dependence, infectious period, latent and carrier periods, and virulence.

Heritability estimates of $\mathrm{BRD}$ resistance in preweaned calves have ranged from 0.10 (Muggli-Cockett et al., 1992) to 0.20 (Snowder et al., 2005). Breed types differ in incidence of $\mathrm{BRD}$ in preweaned calves (Snowder et al., 2005). Whether there are genetic differences among feedlot cattle is not known. Therefore, the objective of this study was to characterize environmental, genetic, and economic factors influencing incidence of BRD in feedlot beef calves.

\section{MATERIALS AND METHODS}

\section{Animals}

Growth and health records of 18,112 cattle in feedlots from 12 breed types (Table 1) were analyzed. Cattle records spanned a 15-yr period (1987 to 2001) for purebred and composite breeds of beef cattle at the US Meat Animal Research Center, Clay Center, NE. Breed types included 9 pure breeds (Angus, Braunvieh, Charolais, Gelbvieh, Hereford, Limousin, Pinzgauer, Red Poll, and Simmental) and 3 composite breeds (MARC I, MARC II, and MARC III). A total of 972 sires and 6,213 dams were parents of the feedlot cattle studied. These animals were part of a germplasm use study conducted to evaluate retention of heterosis and use of breed differences in composite populations (Gregory et al., 1991, 1999). Because an upgrading breeding program had been practiced to develop a few of the purebred groups, animals with seven-eighths and fifteen-sixteenths genes from that breed were considered to be purebred.

Not all 12 breed types were represented across all years. Five breeds (Braunvieh, Pinzgauer, Red Poll, Simmental, and Limousin) were present only from 1987 to 1991. Hereford cattle were fed in the feedlot from 1987 to 1999. Breed types present throughout the entire study included Angus, Charolais, Gelbvieh, and all 3 MARC composites. The number of calves by breed type and year ranged from 59 (Pinzgauer in 1987) to 270 (MARC I in 1987).

Calves were typically born over an average period of $101 \mathrm{~d}$ between mid February and early June. Only single-birth and spring born calves were considered. Preweaning management, pasture description, and supplemental feeding of cows and calves have been previously described by Gregory et al. (1991) and Snowder et al. (2005).

\section{Health Management and Pen Environment}

Feeding and management in the feedlot were described by Gregory et al. (1994a,b). Immediately after weaning, calves were placed in the feedlot pens. Animals were begun on a diet of $2.65 \mathrm{Mcal}$ of ME/kg of dry matter with $15.4 \%$ crude protein. The finishing diet consisted of 2.82 or $3.07 \mathrm{Mcal}$ of ME/kg of dry matter with $11.5 \%$ crude protein. On average across years, animals were fed the starter or backgrounding diet for approximately 5 wk to become adjusted to the finishing diet. The average feeding period was $200 \mathrm{~d}$, with an ADG of $1.0 \mathrm{~kg}$ for all steers and heifers (Table 2). Breedtype effects on growth and efficiency of gain have been previously reported (Gregory et al., 1994a,b, 1995; RiosUtrera et al., 2005).

Calves were placed in the feedlot at an average age of $176 \mathrm{~d}$ and BW of $205 \mathrm{~kg}$ (Table 2). Average ages at weaning of Braunvieh, Pinzgauer, Red Poll, Simmental, and Limousin calves were less than those of the other breed types because the research protocol set a weaning age of approximately $150 \mathrm{~d}$. A drought in 1988 caused calves to be weaned at an average age of $127 \mathrm{~d}$. Average overall weight on feed was $205 \mathrm{~kg}$ but varied by breed. The average calendar day on feed was September 29. The ratio of heifers to steers in the feedlot was 49.5:50.5. 
Table 2. Unadjusted means for age and weight entering the feedlot, days on feed, and ADG by breed type and overall

\begin{tabular}{lcccc}
\hline \hline Breed & $\begin{array}{c}\text { Age, } \\
\text { d }\end{array}$ & $\begin{array}{c}\text { Wt, } \\
\text { kg }\end{array}$ & $\begin{array}{c}\text { Days } \\
\text { on feed }\end{array}$ & $\begin{array}{c}\text { ADG, } \\
\text { kg }\end{array}$ \\
\hline Angus & 189 & 205 & 196 & 1.03 \\
Hereford & 181 & 181 & 194 & 1.01 \\
Charolais & 184 & 218 & 191 & 1.04 \\
Gelbvieh & 182 & 225 & 192 & 0.96 \\
Red Poll & 156 & 177 & 213 & 0.92 \\
Simmental & 150 & 197 & 214 & 1.05 \\
Pinzgauer & 153 & 194 & 214 & 1.01 \\
Braunvieh & 148 & 197 & 214 & 1.00 \\
Limousin & 142 & 163 & 217 & 0.93 \\
MARC I & 173 & 211 & 198 & 0.99 \\
MARC II & 174 & 208 & 201 & 1.01 \\
MARC III & 178 & 204 & 200 & 0.99 \\
\hline Overall & 176 & 205 & 200 & 1.00 \\
\hline
\end{tabular}

Calves were fed separately by sex in mixed breedtype groups. Steers were stratified to pens according to BW. Pens were of 2 sizes, $15 \times 61 \mathrm{~m}\left(915 \mathrm{~m}^{2}\right)$ and $29 \times$ $61 \mathrm{~m}\left(1,769 \mathrm{~m}^{2}\right)$. Periodic removal of steers for serial slaughter caused the number of calves per pen to range from 6 to 72 . There was an average of 17 steers/pen. Heifers were generally fed in the larger pens with more animals per pen in multiple breed-type groups.

All pens were in close proximity at a central feedlot location. The feedlot consisted of 2 rows of 34 pens divided by a roadway. Rows ran in an east-west direction. Additional animals not related to this study were fed in nearby pens. Feed bunks were not shared among pens, but water troughs were shared among adjacent pens. Fence line contact was possible on 2 sides of each pen, except for the end pens.

Calves were often moved among pens for consolidation and veterinary care. At approximately $90 \mathrm{~d}$ on feed or halfway through the feeding period, $74 \%$ of all calves were still in their initial pens. On average, $43 \%$ of all calves remained in their initial pens over the entire feeding period. Therefore, pen assignments could not be used as a classification effect.

Calves were vaccinated before weaning and at weaning before entry into the feedlot. The vaccination program varied across years. Killed virus vaccines used from 1987 to 1992 were replaced with modified live virus vaccines in 1993. A parainfluenza-3 vaccine was added to the calf vaccination program in 1994. At approximately $42 \mathrm{~d}$ of age, calves were vaccinated with an 8-way Clostridial and a 5-way Leptospirial vaccine. At approximately 165 -d of age, calves were given booster vaccinations of Clostridial and Leptospirial vaccines and a modified live virus vaccine for infectious bovine rhinotracheitis, parainfluenza-3, and bovine viral diarrhea.

It is not known whether the epidemiology of BRD observed in this study resembles that of commercial feedlots. Numbers of calves/pen and movement of calves among pens in commercial feedlot enterprises would differ from those in this study. Commercial feedlots also receive cattle from many different locations at different times, increasing the probability of introducing BRD carriers or exposing cattle to different stress factors from those with the closed animal system at US Meat Animal Research Center.

\section{Disease Detection}

Calves were monitored daily by the staff veterinarian or the beef cattle research technicians, or both. Diseases were detected by physical examination, necropsy, or laboratory analyses and were recorded. Typical clinical BRD symptoms for calves included 1 or more of the following: fever, rapid breathing, repetitive coughing, nasal or eye discharge or both, diarrhea, dehydration, and appetite depression. Disease codes related to BRD were combined. The majority of the BRD classifications were from codes for pneumonia and respiratory disease (86 and 11\%, respectively). Additional disease codes included for BRD were bronchitis, emphysema, pleuritis, pulmonary adenomatosis, upper respiratory infection, and pleural fibrosis. Because such diseases may be interpreted as BRD by feedlot staff, it seemed appropriate to include them with the BRD codes. The recoded binary classification listed calves as healthy (code = 200 ) or affected by BRD (code = 100). Records also included calves that died due to BRD symptoms. To avoid multiple measurements on the same calf, which may have been due to lingering respiratory disease or reinfection, only the initially observed infection during the feedlot period was considered.

Additional vaccinations were administered to calves diagnosed with BRD or other ailments. For calves expressing clinical signs of BRD, the calf's age, weight, severity of clinical symptoms, and drug withdrawal time were considered in determining the appropriate treatment. All treatments for BRD included administration of 1 or more medications (oxytetracycline, ceftiofur, flunixin meglumine, florfenicol, tylosin, enrofloxacin, and sulfadimethoxine). Calves with BRD were checked daily and may have received several therapy treatments, as determined by the veterinarian or technical staff, or both. Antibiotics were not routinely administered in the calves' feed or water.

Approximately $13 \%$ of all calves were diagnosed with $\mathrm{BRD}$ during the preweaning period. Because it is not known if BRD infection during the preweaning period affects BRD incidence in the feedlot, a binomial trait for previous exposure was created.

Classification could not be made as to whether an animal was tolerant or resistant to BRD in the feedlot. Tolerance is defined as the ability of an infected animal to show little or no measurable detrimental effect of the disease. Resistance is the ability of the animal to resist infection or control the lifecycle of the infecting microbe. In this study, "resistant" was used to describe an animal that was not detected with clinical symptoms 
Table 3. Total numbers of animals in the pedigree file, numbers of inbred calves, and average inbreeding coefficients $(\mathrm{F})$ of inbred calves by breed type and overall

\begin{tabular}{lrrr}
\hline \hline Breed & Total & Inbred & F, \% \\
\hline Angus & 7,515 & 157 & 3.2 \\
Hereford & 6,017 & 205 & 3.1 \\
Red Poll & 1,233 & 65 & 3.9 \\
Charolais & 3,281 & 847 & 1.7 \\
Gelbvieh & 2,617 & 628 & 1.8 \\
Simmental & 2,217 & 36 & 3.6 \\
Braunvieh & 1,178 & 39 & 3.9 \\
Limousin & 1,220 & 44 & 3.5 \\
Pinzgauer & 1,129 & 64 & 3.8 \\
MARC I & 4,691 & 727 & 1.7 \\
MARC II & 5,406 & 797 & 1.8 \\
MARC III & 11,376 & 1,495 & 2.4 \\
\hline Overall & 47,880 & 5,104 & 2.2 \\
\hline
\end{tabular}

of BRD without regard to whether the animal was truly tolerant, resistant, or not exposed to BRD-causing organisms. The actual trait measured was treatment of observed clinical BRD.

\section{Statistical Procedures}

The pedigree used to calculate the relationship matrix consisted of 47,880 animals born between 1972 and 2001 , including 1,655 sires and 15,648 dams. The number of animals in the pedigree with a nonzero inbreeding coefficient was 6,984 . The average inbreeding coefficient was $2.3 \%$, and ranged from 0.00 to 0.25 (only 161 animals with an inbreeding coefficient greater than 0.10 ). Total numbers of animals in the pedigree by breed type are reported in Table 3 . Of the 18,112 feedlot calves, 5,104 had a nonzero inbreeding coefficient, with an average of $2.2 \%$. The effect of such small levels of inbreeding on BRD incidence was assumed to be negligible.

\section{Descriptive Statistics}

Descriptive statistics for BRD incidence and average age at detection by year and days on feed are given in Tables 4 and 5. Within-breed-type statistics for the percentage of animals with a preweaning BRD record, average age and days on feed when BRD was observed, incidence, mortality, and total death loss (mortality of BRD calves expressed as a percent of all calves) are shown in Table 5.

The general effect of BRD on calf ADG was estimated using the MIXED procedure of SAS (SAS Inst. Inc, Cary, NC). Data were limited to calves that did not die or were not removed for unknown causes $(n=17,936)$ and which were either healthy (no recorded disease code) or diagnosed with BRD. The model included fixed effects for breed type, year of record, sex of calf, health code (healthy, BRD), and interactions of year with health code and breed type. Sire within breed type was included as a random effect. The effect of preweaning BRD infection was not significant in preliminary analyses and therefore was not included in the model. Age at weaning and days on feed were included as linear covariates. Differences in ADG between healthy and diagnosed calves were tested using the F-ratio.

\section{Variance Components}

Data from all purebred and composite breeds were combined into an overall analysis of BRD as the dependent variable. Because some breed types were associated with years, and incidence of BRD was greater from 1987 to 1992 (Figure 1), the data were also partitioned into 3 subsets (Table 1). The first set (EARLY) consisted of all 12 breed types from 1987 to $1991(n=7,039)$. The second set (LATE) included the 7 breed types present from 1992 to $2001(n=9,981)$ when the overall incidence of BRD was less than in previous years. The Hereford breed, although not present in 2000 and 2001, was included in this latter data set. The third set (SELECT) included only the 6 breed types present in all years from 1987 to 2001, plus Herefords ( $n=16,208$ ).

Because incidence of disease influences variance component estimates (Snowder et al., 2005), analyses of EARLY and LATE subsets were performed, respectively, within periods of high (1987 to 1991) and low (1993 to 2001, 1992 exception) BRD incidence. Analysis of the SELECT subset permits appropriate individual breed-type contrasts among the 4 purebred and 3 com-

Table 4. Incidence (\%) of bovine respiratory disease (BRD) in feedlot calves by breed type and year

\begin{tabular}{|c|c|c|c|c|c|c|c|c|c|c|c|c|c|c|c|}
\hline Breed & 1987 & 1988 & 1989 & 1990 & 1991 & 1992 & 1993 & 1994 & 1995 & 1996 & 1997 & 1998 & 1999 & 2000 & 2001 \\
\hline Hereford & 22 & 25 & 30 & 73 & 22 & 24 & 6 & 17 & 8 & 8 & 7 & 19 & 15 & & \\
\hline Gelbvieh & 18 & 11 & 21 & 45 & 32 & 21 & 14 & 11 & 17 & 26 & 5 & 11 & 7 & 6 & 3 \\
\hline Red Poll & 14 & 16 & 18 & 34 & 30 & & & & & & & & & & \\
\hline Simmental & 15 & 27 & 31 & 45 & 45 & & & & & & & & & & \\
\hline Limousin & 23 & 12 & 37 & 48 & 43 & & & & & & & & & & \\
\hline MARC I & 25 & 8 & 24 & 38 & 28 & 26 & 10 & 21 & 4 & 19 & 5 & 3 & 2 & 6 & 1 \\
\hline MARC II & 17 & 21 & 32 & 49 & 36 & 22 & 6 & 14 & 14 & 12 & 4 & 6 & 5 & 6 & 17 \\
\hline MARC III & 15 & 20 & 22 & 40 & 27 & 17 & 7 & 9 & 8 & 11 & 4 & 7 & 4 & 4 & 12 \\
\hline
\end{tabular}




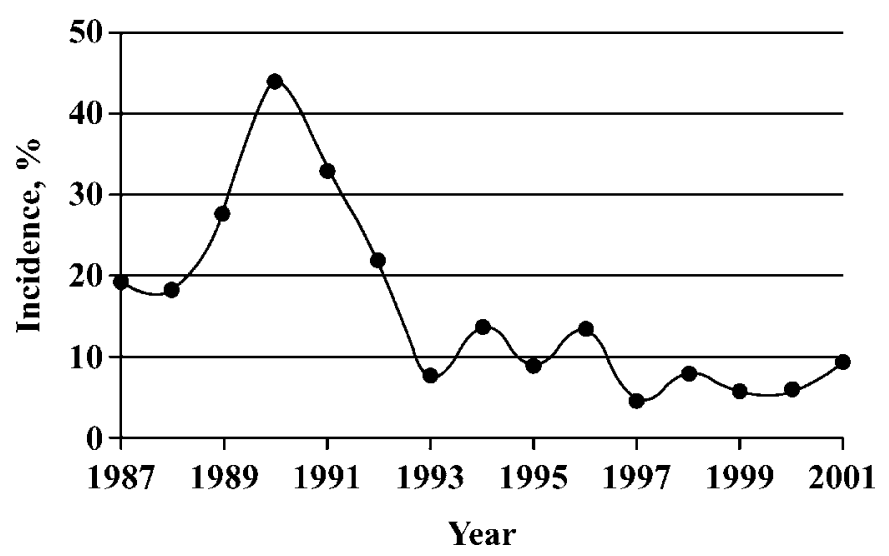

Figure 1. Incidence rates (\%) of observed bovine respiratory disease in feedlot cattle by year.

posite breed types across all years. This latter analysis may be more informative of breed-type differences than analysis of the LATE subset.

The effect of heterozygosity was inferred by contrasting individual composite breeds with each pure breed. More appropriately, composite breeds were further contrasted with all purebreds using appropriate coefficients for the purebreds based on their total contribution to the composite breeds.

Variance components for incidence of BRD were estimated using a single-trait model with a derivative-free REML algorithm (Graser et al., 1987) by using the computer programs of Boldman et al. (1995). Convergence was considered to have been reached when the variance of the $-2 \log \mathrm{L}$ in the simplex was less than $1 \times 10^{-6}$. After initial convergence, 4 restarts were performed to ensure global convergence as determined when the -2 $\log \mathrm{L}$ did not change to the second decimal. Standard error of the heritability estimate was based on the average information matrix and the delta method (e.g., Dodenhoff et al., 1998). Fixed effects in the model included year, breed type, and sex of calf. Initial weight on entering the feedlot and total days on feed were included as covariates. Calf (genetic direct) was a random effect. Because breed types were confounded with years, and incidence of BRD varied with groups of years, breed type by year was regarded as an uncorrelated random effect. This approach allows the SE to account for the interaction variance and the residual variance, which in turn requires a much larger difference in breed-type solutions to be significant. All subsets were analyzed with the same model. Contrasts between solutions for sex of calf and breed types for BRD incidence were tested with a Student's $t$-test. Individual breed-type solutions were deviated from the solution for the Angus breed.

Because BRD incidence is a dichotomous threshold trait and because not all animals were likely to have had equal opportunity to become infected and express their true phenotype, it is reasonable to assume there is an underlying scale of genetic variation (Robertson

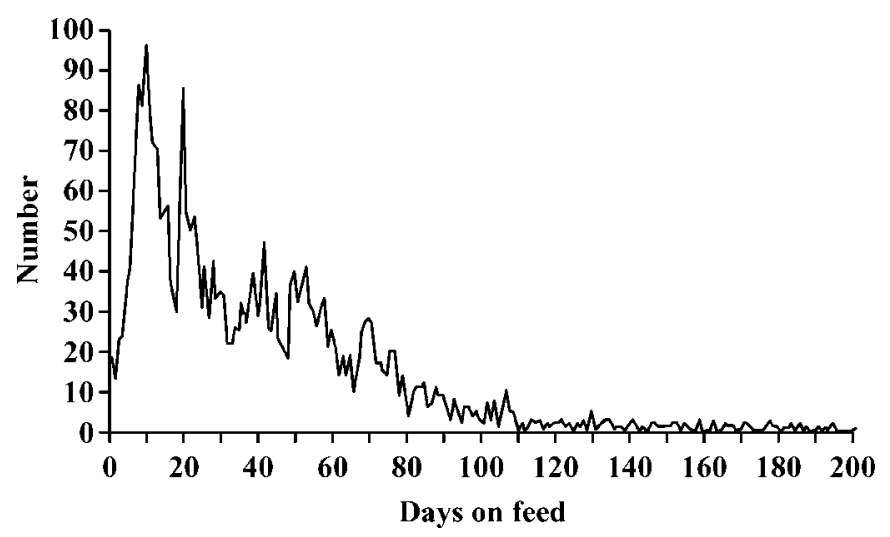

Figure 2. Number of feedlot calves observed with bovine respiratory disease by days on feed.

and Lerner, 1949). The overall estimate of heritability for BRD on the observed scale was transformed to a heritability estimate on the underlying continuous normal scale (Robertson's appendix to Dempster and Lerner, 1950).

\section{RESULTS AND DISCUSSION}

The use of field data, or even experimental data obtained under an extensive management systems such as at MARC, to estimate genetic factors associated with diseases has obvious limitations. Distinguishing between phenotypes of healthy and sick animals is not always accurate. Animals infected with the same disease may express different clinical symptoms and degree of expression may vary. The number of animals exposed to the disease is dependent on the epidemic level, which fluctuates with the degree of disease challenge. Therefore, disease-free animals may be healthy because they were not exposed or were not sufficiently exposed to disease organisms. A disease may also result from a secondary infection rather than from a primary infection so that resistance to a disease may partially depend on resistance to the primary disease. Diseases that are time, age, or season dependent or transitional over time may not be accurately detected in all susceptible populations. Because not all animals are equally exposed to the disease-causing organism under most field conditions, the underlying genetic variation may be greater than the variation observed for disease resistance (Dempster and Lerner, 1950).

\section{Characteristics of $B R D$}

The incidence of BRD varied across the 15-yr span (Figure 1) and ranged from 4.6 to $43.8 \%$ per year with an average annual incidence of $17.0 \%$. The greatest incidences were from 1987 to 1992. Epidemic proportions were observed in 1990 and 1991. In 1990, observed incidences within breed type ranged from 28 to $73 \%$ (Braunvieh and Hereford, respectively; Table 4). Sev- 
Table 5. Incidence of bovine respiratory disease (BRD) in calves before feedlot, average age and days on feed when BRD was diagnosed, incidence rate of BRD, mortality among calves with BRD, and total death loss due to BRD among all calves by breed type and overall $^{1}$

\begin{tabular}{lcccccc}
\hline \hline & $\begin{array}{c}\text { BRD } \\
\text { before } \\
\text { Breed }\end{array}$ & Age, d & $\begin{array}{c}\text { Days on } \\
\text { feed }\end{array}$ & $\begin{array}{c}\text { Incidence, } \\
\%\end{array}$ & $\begin{array}{c}\text { Mortality, } \\
\%\end{array}$ & $\begin{array}{c}\text { Total } \\
\text { death, } \\
\%\end{array}$ \\
\hline Angus & 12.9 & 205 & 35 & 10.2 & 1.9 & 0.5 \\
Hereford & 8.6 & 206 & 43 & 18.5 & 4.5 & 0.9 \\
Charolais & 11.9 & 213 & 46 & 13.7 & 5.8 & 1.4 \\
Gelbvieh & 11.5 & 211 & 41 & 14.8 & 3.4 & 0.9 \\
Red Poll & 17.6 & 201 & 50 & 22.2 & 8.9 & 2.1 \\
Simmental & 14.7 & 190 & 48 & 33.2 & 4.4 & 1.7 \\
Pinzgauer & 13.0 & 200 & 49 & 35.0 & 3.4 & 1.2 \\
Braunvieh & 25.5 & 198 & 56 & 34.0 & 0.1 & 1.1 \\
Limousin & 13.3 & 190 & 52 & 32.3 & 3.7 & 1.4 \\
MARC I & 16.5 & 201 & 41 & 15.9 & 5.1 & 1.1 \\
MARC II & 9.6 & 196 & 39 & 18.8 & 3.1 & 0.9 \\
MARC III & 13.3 & 202 & 42 & 14.6 & 3.6 & 0.8 \\
\hline Overall & 12.8 & 202 & 43 & 17.0 & 3.9 & 1.0 \\
\hline
\end{tabular}

${ }^{1}$ Mortality included calves that died or were culled for reasons associated with BRD.

eral factors may have contributed to greater incidences in earlier years. These factors included the use of less effective killed vaccines from 1987 to 1992 compared with modified live vaccines used from 1993 to 2001, adding parainfluenza-3 vaccine to the calf vaccination program in 1995, and changing the castration method from surgical (1987 to 1989) to mechanical banding (1990 to 2001). After 1992, the annual overall incidence remained less than 14\%, although there were occasional high incidences for some breed types such as 20 and 21\% for Charolais and MARC I in 1994 and 26\% for Gelbvieh in 1996 (Table 4). The average incidence of BRD in 1999 for 520 US commercial feedlots was reported to be $14.4 \%$ (NAHMS, 2000a) and to be $20.6 \%$ for 17 Iowa feedlots from 1988 to 1997 (Faber et al., 1999). Large variations in morbidity due to $\mathrm{BRD}$ ranging from 0 to $59 \%$ were reported in Iowa for 20 feedlots across 10 yr (Faber et al., 1999).

The average age when feedlot calves were treated for BRD was $202 \pm 51 \mathrm{~d}$ and ranged from 109 to $522 \mathrm{~d}$. The number of calves with BRD treated per day across all years was associated with days on feed (Figure 2). A dramatic increase in incidence was observed after $5 \mathrm{~d}$ in the feedlot. Incidence of BRD peaked within $14 \mathrm{~d}$ on feed and remained high until approximately $80 \mathrm{~d}$ on feed. After $110 \mathrm{~d}$ on feed the numbers of calves observed with BRD per day were negligible. The epidemiological pattern observed is similar to that previously reported in feedlot cattle by Loneragan (2001) for BRD and by Schunicht et al. (2003) for undifferentiated disease treatment.

The relationship of BRD illness during the preweaning period to $\mathrm{BRD}$ incidence in the feedlot has not been previously reported. Approximately $13 \%(\mathrm{n}=2,318)$ of all calves were previously detected with preweaning BRD infection (Table 5). Effects of breed type and envi- ronment on incidence of BRD in calves before weaning have been previously reported (Snowder et al., 2005). Preweaning incidence was greatest in Braunvieh calves and lowest in Hereford calves. Among feedlot calves with previously observed $\mathrm{BRD}, 18 \%(\mathrm{n}=417)$ were also detected with BRD in the feedlot. Among feedlot calves with no previous record of BRD ( $\mathrm{n}=15,794), 16 \%(\mathrm{n}=$ $2,524)$ were detected with BRD. The effect of previous BRD infection was not a significant effect when analyzing feedlot traits for ADG and BRD incidence $(P=0.36$ and 0.24 , respectively).

\section{Effect of Sex of Calf}

Overall incidence of BRD differed $(P<0.05)$ between steers and heifers (20 vs. 14\%, respectfully). During years of high incidence (1987 to 1991), male calves made up approximately $62 \%$ of all reported cases of BRD but only 54\% during years of low incidence (1992 to 2001). Castration before entry into the feedlot may predispose male calves to BRD infection. The change in castration procedure in 1990 may partially account for the difference in BRD incidence between the 2 periods. From an extensive review of literature, Bretschneider (2005) concluded that age of castration had a significant effect on $\mathrm{ADG}$ for the first $30 \mathrm{~d}$ postcastration and on stress response, and that rubber banding methods were less stressful than surgical castration. Management of steers differed slightly with fewer animals per pen and more frequent weighing than heifers. The interaction of breed type and sex of calf effects was not significant in preliminary analyses.

\section{Effect of Breed Type}

Unadjusted averages for traits related to $B R D$ varied among breed types (Table 5). Average age when BRD 
Table 6. Solutions by breed type for incidence of bovine respiratory disease (BRD) and $t$-values for contrasts for pairs of breed solutions in subset EARLY (1987-1991) ${ }^{1}$

\begin{tabular}{lcccr}
\hline \hline & & \multicolumn{3}{c}{$t$-test $>1.7$} \\
\cline { 3 - 5 } Breed & Solution & Simmental & Hereford & Pinzgauer \\
\hline MARC I & -4.22 & 1.78 & $2.04^{*}$ & $2.21^{*}$ \\
Gelbvieh & -2.86 & 1.78 & & \\
MARC III & -2.61 & & & \\
Red Poll & -1.35 & & & \\
Charolais & -0.07 & & & \\
Angus & 0 & & & \\
MARC II & 1.78 & & & \\
Limousin & 3.84 & & & \\
Braunvieh & 4.56 & & & \\
Simmental & 5.55 & & & \\
Hereford & 7.04 & & & \\
Pinzgauer & 7.94 & & & \\
\hline
\end{tabular}

${ }^{1}$ Solutions expressed as differences from Angus.

*Indicates difference as statistically significant $(P<0.05)$.

was detected did not vary greatly among breed types with an overall average of $202 \mathrm{~d}$. Limousin and Simmental had the youngest average ages (190 d), whereas Charolais had the oldest average age ( $213 \mathrm{~d})$. The average number of days on feed when BRD was detected was $43 \mathrm{~d}$, ranging by breed type from 35 to $56 \mathrm{~d}$ (Angus and Braunvieh, respectively).

The unadjusted mean incidence for BRD was lowest for Angus, 10.2\% (Table 5). Charolais, Gelbvieh, MARC I and III cattle also had lower unadjusted mean incidences. Incidence of BRD was greatest for Pinzgauer, Braunvieh, Simmental, and Limousin (35, 34, 33, and $32 \%$, respectively).

When only years of 1987 through 1991 (EARLY) were considered (the year for which records were available for all 9 pure breeds and 3 composites), high incidences were observed in all breed types. Incidence by year and breed type ranged from 7 to $73 \%$ (Table 4). Solutions to the mixed model equations indicated that the only significant differences were between MARC I calves and Hereford and Pinzgauer calves (Table 6).

For years of low incidence (1992 through 2001, LATE), breed-type solutions were not different $(P>$ 0.05 ; Table 7 ). When breed types present in all years
(1987 to 2001, SELECT) were considered, the large solution for Herefords differed $(P<0.05)$ from solutions for Angus, MARC I, and MARC II (Table 8). The extremely large incidence of $73 \%$ in 1990 (Table 4) for the Herefords may be a main reason for these differences. Greater incidences of BRD in the Herefords during 1998 and 1999 (19 and 15\%, respectively) compared with lower incidences in Angus, MARC I, and MARC II calves (2 to 7\%; Table 4) may have influenced these differences.

Death losses were generally low for most breed types (Table 5). Approximately 4\% of calves detected with BRD died, which contributed to a total death loss of $1 \%$. In a national feedlot monitoring program, the proportion of total death losses attributed to BRD increased from $52.1 \%$ in 1994 to $61.5 \%$ in 1999 with an average annual total death loss of $1.2 \%$ (NAHMS, $2000 \mathrm{~b}$ ). Changes in the cattle and feedlot industries may have contributed to the increased death loss observed nationally such as younger calves being fed longer, lack of knowledgeable and experienced feedlot labor to detect $\mathrm{BRD}$, lack of preweaning vaccinations, and negligible prevention at the producer level (Ishmael, 2001).

Mortality of calves detected with BRD was greatest in the Red Poll (8.9\%). Mortality of Red Poll calves before weaning attributed to BRD was previously reported to be greater than for most other breed types (Snowder et al., 2005). The greater mortality rate among Red Poll calves before weaning and during the feedlot period suggests this breed may be more sensitive to clinical BRD infection compared with other breed types.

No apparent advantage for heterozygosity to BRD resistance (incidence or mortality) could be detected from individual contrasts of composite breeds with each pure breed. Although the solutions for MARC I and III composite calves were favorable for resistance compared with most other breed types (Table 6, 7, and 8), those composite breeds were not less susceptible than other breed types $(P>0.05)$ except when compared with the Herefords. The group contrast of all 3 composites with all 9 pure breeds was not significant $(P>0.05)$. Therefore, heterozygosity cannot be considered as a significant factor on resistance to BRD.

Table 7. Solutions by breed type for incidence of bovine respiratory disease (BRD) and $t$-values for contrasts for pairs of breed solutions in subset LATE (1992-2001) ${ }^{1,2}$

\begin{tabular}{lccccccc}
\hline \hline Breed & Solution & Hereford & Charolais & Gelbvieh & MARC I & MARC II & MARC III \\
\hline Angus & 0.00 & 1.62 & 1.04 & 1.54 & 0.74 & 1.43 & 0.40 \\
Hereford & 4.23 & & 0.55 & 0.05 & 0.86 & 0.20 & 1.11 \\
Charolais & 2.72 & & & 0.49 & 0.30 & 0.35 & 0.58 \\
Gelbvieh & 4.09 & & & & 0.80 & 0.15 & 1.05 \\
MARC I & 1.90 & & & & & 0.67 & 0.30 \\
MARC II & 3.68 & & & & & & 0.93 \\
MARC III & 1.08 & & & & & & \\
\hline
\end{tabular}

\footnotetext{
${ }^{1}$ Solutions expressed as differences from Angus.

${ }^{2}$ No differences were statistically significant.
} 
Table 8. Solutions by breed type for incidence of bovine respiratory disease (BRD) and $t$-values for contrasts for pairs of breed solutions in subset SELECT (1987-2001) ${ }^{1}$

\begin{tabular}{lccc}
\hline \hline & & \multicolumn{2}{c}{$t$-test $>1.7$} \\
\cline { 3 - 4 } Group & Solution & Hereford & MARC II \\
\hline Angus & 0.00 & $2.53^{*}$ & 1.76 \\
MARC III & 0.43 & $2.13^{*}$ & \\
MARC I & 0.99 & $2.11^{*}$ & \\
Gelbvieh & 2.48 & & \\
Charolais & 3.08 & & \\
MARC II & 4.51 & & \\
Hereford & 6.70 & & \\
\hline
\end{tabular}

${ }^{1}$ Solutions expressed as differences from Angus.

*Indicates difference as statistically significant $(P<0.05)$.

\section{Heritability of $B R D$}

Estimates of heritability of resistance to BRD in the feedlot were low, ranging from $0.04 \pm 0.01$ to $0.08 \pm$ 0.01 (Table 9). No previous estimates could be found in the literature. However, these estimates are similar to estimates reported for calves before weaning by MuggliCockett et al. (1992, $0.10 \pm 0.02)$ and Snowder et al. (2005, $0.07 \pm 0.01$ to $0.19 \pm 0.01$ ). The larger estimate for the EARLY data set (years of high incidence) compared with the smaller estimate from the LATE data set (years of low incidence) supports the conclusion by Snowder et al. (2005) that greater heritability estimates are related to greater incidences as more animals are challenged to express their phenotype for disease resistance.

Heritability for incidence of BRD on an underlying continuous normal scale was estimated to be 0.18 using the heritability estimate of 0.08 (Table 9 ), and the overall annual average BRD incidence of $17 \%$ (Table 5). The larger heritability estimate for the underlying continuous scale implies selection for BRD could be effective provided all animals are challenged adequately. Thus, development of an inexpensive and humane method of challenging animals for BRD resistance would seem an important step in developing a selection program to reduce incidence of $\mathrm{BRD}$.
The results of this study suggest that selection against susceptibility to BRD using producer or industry recorded data is feasible, which agrees with conclusions of previous reports that producer-recorded data can be useful for genetic selection to reduce diseases, reproductive disorders, and metabolic disorders (Zwald et al., 2004a,b).

\section{Implications to Management}

Although BRD is a disease of foremost concern because of its widespread incidence in cattle (Callan and Garry, 2002), BRD can be controlled by decreasing pathogen transmission between animals. Management practices that reduce pathogen introduction, exposure, and transmission are important initial steps. Total eradication of pathogens for BRD is not likely in feedlot environments where introduction of cattle and movement of cattle are usual management activities. Decreasing pathogen transmission between animals can be achieved by removing affected animals and avoiding crowding of animals. Another approach is to reduce the number of susceptible animals by increasing the number of BRD-resistant animals, which can be achieved by the use of vaccines or antibiotics, although some pathogens may be resistant to antibiotics and efficacy of vaccines may be limited in some cases. Vaccines can be effective for reducing not only susceptibility but also for reducing shedding of infectious BRD agents to other calves (Frank et al., 1994, 2003). In some cases antibiotics will not make the animal resistant but, for example, can reduce carriage and shedding of $M$. haemolytica (Frank et al., 2000, 2002). Another approach is to select for individuals resistant to BRD. All animals in a population need not be resistant to prevent an epidemic if enough animals resistant to the disease are present to prevent spread to susceptible animals (Anderson and May, 1992; Bishop and MacKenzie, 2003).

Pathogens resulting in $\mathrm{BRD}$ in this study were probably not of a single variety, but rather could have been of bacterial, viral, or mycoplasmal origin, or some combination of these. If this assumption is correct, then selection for BRD resistance or tolerance based on com-

Table 9. Estimates of components of variance for incidence of bovine respiratory disease (BRD) over all breed types of feedlot calves by data set

\begin{tabular}{|c|c|c|c|c|}
\hline \multicolumn{5}{|c|}{ Estimate $^{1}$} \\
\hline Data set $^{2}$ & $\sigma_{\mathrm{p}}^{2}, \%^{2}$ & $\sigma_{\mathrm{a}}^{2}, \%^{2}$ & $\sigma_{\mathrm{b}}^{2}, \%^{2}$ & $\mathrm{~h}^{2}$ \\
\hline ALL & 1,246 & 93 & 25 & $0.08 \pm 0.01$ \\
\hline EARLY & 1,815 & 136 & 37 & $0.07 \pm 0.01$ \\
\hline LATE & 757 & 32 & 17 & $0.04 \pm 0.01$ \\
\hline SELECT & 1,153 & 79 & 21 & $0.07 \pm 0.01$ \\
\hline
\end{tabular}


mon treatment or incidence records may result in an improved generalized disease defense mechanism, possibly a more efficacious immune system. Previous studies demonstrated that selection for antibody or cellmediated immune responses, or both, improve health and production in cattle (Hernández et al., 2003), swine (Mallard et al., 1992 and 1998), and poultry (Pinardvan der Laan et al., 1999). Further investigation of the genetic mechanisms of disease resistance is certainly warranted.

\section{Economic Effect}

The general economic effect of BRD on feedlot cattle was determined by its effect on ADG and calf death loss, ignoring treatment costs. All fixed factors in the linear model to examine the effect of BRD on ADG were significant with the model accounting for $80 \%$ of the variation. Calves diagnosed with BRD had lower $(P<$ $0.001) \mathrm{ADG}(0.95 \mathrm{~kg})$ compared with healthy animals $(0.99 \mathrm{~kg})$. Over a 200 -d feeding period, an $8-\mathrm{kg}$ difference between a healthy and an infected calf could be expected. This is in agreement with Bateman et al. (1990) who observed a $0.06 \mathrm{~kg}$ difference for ADG between healthy and calves treated for BRD on feed for 138 to 235 d. However, Faber et al. (1999) reported that after cattle were effectively treated for $\mathrm{BRD}$, compensatory gain was sufficient such that no difference in $\mathrm{ADG}$ was observed over the entire 220-d feeding period. Compensatory gain by BRD-affected calves was also inferred by Bateman et al. (1990) who reported that ADG of BRD affected calves was $0.14 \mathrm{~kg}$ less than healthy calves after $28 \mathrm{~d}$ but that this difference diminished to $0.06 \mathrm{~kg}$ after 135 to $238 \mathrm{~d}$ on feed. Because the greatest incidence of BRD generally occurs early in the feedlot, prompt detection and proper treatment would contribute to a calf's recovery and subsequent compensatory gain.

A feedlot with 1,000 calves and a $14.4 \%$ incidence (NAHMS, 2000a) could expect a loss of $1,152 \mathrm{~kg}$ plus treatment costs attributed to BRD. Based on the current slaughter cattle price of $\$ 1.83 / \mathrm{kg}$ (USDA, AMS, $2005)$, the value in lost gain attributed to BRD would be $\$ 2,108$ per 1,000 animals, assuming calves are slaughtered after $200 \mathrm{~d}$ on feed. Additionally, if treatment costs for medication and related items averaged $\$ 15.57$ per sick animal (Faber et al., 1999; USDA APHIS, 2001), then an additional loss of $\$ 1,813$ could be attributed to treating 144 infected calves. A death loss of $1 \%$ due to BRD (Table 5) would cost $\$ 9,974$ (10 calves with average market weight of $545 \mathrm{~kg}$ at slaughter at $\$ 1.83 \mathrm{~kg}$, USDA AMS, 2005). Estimated total economic loss per 1,000 animals would be $\$ 13,895$, not including feed costs before the death of calves, labor and associated handling costs. A survey of cattle feedlots in Iowa estimated that steers not infected with BRD returned \$57.48 more per steer (Faber et al., 1999). Overall economic loss due to BRD may be difficult to determine because animals not exhibiting overt clini- cal symptoms can have suppressed gains (Wittum et al., 1996).

\section{IMPLICATIONS}

This study contributes to knowledge of environmental and genetic factors influencing bovine respiratory disease. The population characteristics and epidemiological pattern found in this study should be useful for prevention and management of respiratory disease. Beef cattle producers also are provided with evidence that relatively small differences for resistance to bovine respiratory disease exist between breed types. There is no strong evidence that composite breeds are less susceptible to bovine respiratory disease. Although the estimate of observed heritability for incidence of respiratory disease was low, the estimate of heritability for the underlying scale was moderate, which suggests that selection for disease resistance could be effective. Future research is needed to determine how best to identify resistant animals.

\section{LITERATURE CITED}

Anderson, R. M., and R. M. May. 1992. Infectious Diseases of Humans. Dynamics and Control. Oxford Univ. Press, Oxford, UK.

Bateman, K. G., W. Martin, P. E. Shewen, and P. I. Menzies. 1990. An evaluation of antimicrobial therapy for undifferentiated bovine respiratory disease. Can. Vet. J. 31:689-696.

Bishop, S. C., and K. M. MacKenzie. 2003. Genetic management strategies for controlling infectious diseases in livestock populations. Genet. Sel. Evol. 35(Suppl. 1):S3-S17.

Boldman, K. G., L. A. Kriese, L. D. Van Vleck, C. P. Van Tassell, and S. D. Kachman. 1995. A Manual for Use of MTDFREML. A set of programs to obtain estimates of variances and covariances. U.S. Dep. Agric., Agric. Res. Service, Clay Center, NE.

Bretschneider, G. 2005. Effects of age and method of castration on performance and stress response of beef male cattle: A review. Livest. Prod. Sci. 97:89-100.

Callan, R. J., and F. B. Garry. 2002. Biosecurity and bovine respiratory disease. Vet. Clin. Food Anim. 18:57-77.

Dempster, E. R., and I. M. Lerner. 1950. Heritability of threshold characters. Genetics 35:212-236.

Dodenhoff, J., L. D. Van Vleck, S. D. Kachman, and R. M. Koch. 1998. Parameter estimates for direct, maternal and grandmaternal genetic effects for birth weight and weaning weight in Hereford cattle. J. Anim. Sci. 76:2521-2527.

Ellis, J. A. 2001. The immunology of the bovine respiratory disease complex. Vet. Clin. Food Anim. 17:535-549.

Faber, R., N. Hartwig, D. Busby, and R. BreDahl. 1999. The costs and predictive factors of bovine respiratory disease in standardized steer tests. A. S. Leaflet R1648. 1999 Beef Research Report. Iowa State Univ. Press, Ames.

Frank, G. H., R. E. Briggs, G. C. Duff, and H. S. Hurd. 2003. Effect of intranasal exposure to eukotoxin-deficient Mannheimia haemolytica at the time of arrival at the feedyard on subsequent isolation of $M$. haemolytica from nasal secretions of calves. Am. J. Vet. Res. 64:580-585.

Frank, G. H., R. E. Briggs, G. C. Duff, R. W. Loan, and C. W. Purdy. 2002. Effects of vaccination before transit and administration of florfenicol at time of arrival in a feedlot on the health of transported calves and detection of Mannheimia haemolytica in nasal secretions. Am. J. Vet. Res. 63:251-256.

Frank, G. H., R. E. Briggs, R. W. Loan, C. W. Purdy, and E. S. Zehr. 1994. Serotype-specific inhibition of colonization of the tonsils and nasopharynx of calves after Pasteurella haemolytica sero- 
type A1 vaccination with the organism. Am. J. Vet. Res. 55:1107-1110.

Frank, G. H., R. E. Briggs, R. W. Loan, C. W. Purdy, and E. S. Zehr. 2000. Effects of tilmicosin treatment on Pasteurella haemolytica organisms in nasal secretion specimens of calves with respiratory tract disease. Am. J. Vet. Res. 61:525-529.

Graser, H. U., S. P. Smith, and B. Tier. 1987. A derivative-free approach for estimating variance components in animal models by restricted maximum likelihood. J. Anim. Sci. 64:1362-1370.

Gregory, K. E., L. V. Cundiff, and R. M. Koch. 1991. Breed effects and heterosis in advanced generations of composite populations for preweaning traits of beef cattle. J. Anim. Sci. 69:947-960.

Gregory, K. E., L. V. Cundiff, and R. M. Koch. 1994a. Breed effects, dietary energy density effects, and retained heterosis on different measures of gain efficiency in beef cattle. J. Anim. Sci. 72:1138-1154.

Gregory, K. E., L. V. Cundiff, and R. M. Koch. 1995. Genetic and phenotypic (co)variances for growth and carcass traits of purebred and composite populations of beef cattle. J. Anim. Sci. 73:1920-1926.

Gregory, K. E., L. V. Cundiff, and R. M. Koch. 1999. Composite Breeds to Use Heterosis and Breed Differences to Improve Efficiency of Beef Production. Technical Bulletin. No. 1875. ARS-USDA, Clay Center, NE.

Gregory, K. E., L. V. Cundiff, R. M. Koch, M. E. Dikeman, and M. Koohmaraie. 1994b. Breed effects and retained heterosis for growth, carcass, and meat traits in advanced generations of composite populations of beef cattle. J. Anim. Sci. 72:833-850.

Hernández, A., N. Karrow, and B. A. Mallard. 2003. Evaluation of immune responses of cattle as a means to identify high or low responders and use of a human microarray to differentiate gene expression. Genet. Sel. Evol. 35(Suppl. 1):S67-S81.

Ishmael, W. 2001. Gasping for dollars. Angus Beef Bulletin. Angus Productions Inc., St. Joseph, MO, 64506. Available: http:// www.angusbeefbulletin.com/ArticlePDF/ 0901abb_GaspingforDollars.pdf Accessed Sep. 23, 2005.

Loneragan, G. H. 2001. Acute interstitial pneumonia, bovine respiratory disease complex and potential pneumotoxicity in feedlot cattle. Ph.D. Diss., Colorado State Univ., Fort Collins.

Mallard, B. A., B. N. Wilkie, B. W. Kennedy, J. Gibson, and M. Quinton. 1998. Immune responsiveness in swine: Eight generations of selection for high and low immune response in Yorkshire pigs. Proc. 6th World Congr. Gene. Appl. Livest. Prod., Armidale, Australia XXVII:257-262.

Mallard, B. A., B. N. Wilkie, B. W. Kennedy, and M. Quinton. 1992. Use of estimated breeding values in a selection index to breed Yorkshire pigs for high and low immune and innate resistance factors. Anim. Biotechnol. 3:257-280.

Muggli-Cockett, N. E., L. V. Cundiff, and K. E. Gregory. 1992. Genetic analysis of bovine respiratory disease in beef calves during the first year of life. J. Anim. Sci. 70:2013-2019.
NAHMS. 2000a. Feedlot '99 Part II: Baseline Reference of Feedlot Health and Health Management. USDA, APHIS, National Animal Health Monitoring System. Available: http://www.aphis.usda.gov/vs/ceah/ncahs/nahms/feedlot/\#feedlot99 Accessed Aug. $22,2005$.

NAHMS. 2000b. Changes in the U.S. Feedlot Industry: 1994-1999. USDA, APHIS, National Animal Health Monitoring System. Available: http://www.aphis.usda.gov/vs/ceah/ncahs/ nahms/ feedlot/feedlot99/Fd99changes.pdf Accessed Sept. 21, 2005.

Pinard-van der Laan, M. H., P. B. Siegel, and S. J. Lamont. 1999. Lessons from selection experiments on immune response in the chicken. Poult. Avian Biol. Rev. 9:125-141.

Rios-Utrera, A., L. V. Cundiff, K. E. Gregory, R. M. Koch, M. E. Dikeman, M. Koohmaraie, and L. D. Van Vleck. 2005. Genetic analysis of carcass traits of steers adjusted to age, weight, or fat thickness slaughter end points. J. Anim. Sci. 83:764-776.

Robertson, A., and I. M. Lerner. 1949. The heritability of all-or-none traits: Viability of poultry. Genetics 34:395-411.

Schunicht, O. C., C. W. Booker, G. K. Jim, P. T. Guichon, B. W. Wildman, and B. W. Hill. 2003. Comparison of a multivalent viral vaccine program versus a univalent viral vaccine program on animal health, feedlot performance, and carcass characteristics of feedlot calves. Can. Vet. J. 44:43-48.

Smith, R. A. 1998. Impact of disease on feedlot performance: a review. J. Anim. Sci. 76:272-274.

Snowder, G. D., L. D. Van Vleck, L. V. Cundiff, and G. L. Bennett. 2005. Influence of breed, heterozygosity, and disease incidence on estimates of variance components of respiratory disease in preweaned beef calves. J. Anim. Sci. 83:1247-1261.

USDA. AMS. 2005. National Daily Feeder and Stocker Cattle AM Summary St. Joseph, Missouri, Wed., Sept. 14, 2005. Available: http://www.ams.usda.gov/LSMNpubs/PDF_Daily/DFSS.pdf Accessed Sep. 14, 2005.

USDA. APHIS. 2001. Treatment of respiratory disease in U.S. feedlots. Info Sheet APHIS Veterinary Services. Available: www.aphis.usda.gov/vs/ceah/ncahs/nahms/feedlot/ feedlot99/ FD99treatresp.pdf Accessed Sept. 15, 2005.

Wittum, T. E., N. E. Woollen, L. J. Perino, and E. T. Littledike. 1996. Relationships among treatment for respiratory tract disease, pulmonary lesions evident at slaughter and rate of weight gain in feedlot cattle. J. Am. Vet. Med. Assoc. 209:814-818.

Zwald, N. R., K. A. Weigel, Y. M. Chang, R. D. Welper, and J. S. Clay. 2004a. Genetic selection for health traits using producerrecorded data. I. Incidence rates, heritability estimates, and sire breeding values. J. Dairy Sci. 87:4287-4294.

Zwald, N. R., K. A. Weigel, Y. M. Chang, R. D. Welper, and J. S. Clay. 2004b. Genetic selection for health traits using producerrecorded data. II. Genetic correlations, disease probabilities, and relationships with existing traits. J. Dairy Sci. 87:4295-4302. 